\title{
A NOVEL PROJECT-BASED MULTIDISCIPLINARY DESIGN EXPERIENCE
}

\author{
Kamran Behdinan, Narges Balouchestani Asli \\ Institute for Multidisciplinary Design \& Innovation (IMDI), University of Toronto \\ behdinan@mie.utoronto.ca,narges.balouchestaniasli@mail.utoronto.ca
}

\begin{abstract}
This paper presents the new multidisciplinary project based course at the graduate level. We explore how this novel course has been evolved from our multidisciplinary capstone course in the undergraduate level. We also introduce a new addition to our framework for multidisciplinary project based design courses, which is the faculty expert zone. This addition will enhance the students' multidisciplinary project based experience by providing a support system for wide ranges of projects that is offered by these courses. We also investigate qualitative and quantitative feedback from our students regarding the proposed framework that reflect students' experiences.
\end{abstract}

Keywords: Multidisciplinary Education, Capstone, Design, Graduate Studies, Subject Matter Experts

\section{INTRODUCTION}

The role of an engineer has evolved over time. Nowadays, graduating engineers join a workplace that requires them to function in a multidisciplinary environment. To be a successful engineer in the $21^{\text {st }}$ century, an engineer should be able to communicate his/her knowledge to both engineers and non-engineers. The ability to work in a multidisciplinary team is becoming a significantly important criterion for engineers. To address this need, many educational institutions have started to incorporate multidisciplinary work in their circular. From 2005 to 2012, in US only, approximately $35 \%$ of engineering capstone design courses have changed to include multidisciplinary aspects in their content [1]. The framework of the multidisciplinary experience differs from one institution to another based on the resources available in each institution. Some universities have a combination of students from only two different disciplines within engineering, while others have students from engineering working with students from other faculties like architecture, medicine, psychology, etc. At the University of Toronto, we brought together everyone within the Faculty of Applied Science and Engineering to introduce the multidisciplinary capstone course at the 2013-2014 school year. The course is offered under the Institute for Multidisciplinary Design \& Innovation (IMDI) that was established by Professor Behdinan. Students from 6 departments and 3 institutions within the Faculty of Applied Science and Engineering (Electrical and Computer Engineering, Mechanical and Industrial Engineering, Chemical Engineering and Applied Chemistry, Material Science and Engineering, Civil Engineering, Engineering Science, Institute of Biomaterial and Biochemical Engineering, Institute of Robotics and Mechatronics, and Institute of Multidisciplinary Design and Innovation) are participating in our multidisciplinary capstones experience. Students from the Computer Science department of the Faculty of Art and Science also joined the team in 2015-2016 academic year. Our multidisciplinary capstone course prepares student for the real world experience after graduation by providing projects of multidisciplinary nature from the industry partners. Our multidisciplinary course is offered as a full year course from September to April that encompasses all design stages from idea generation to prototyping. For each team there is an assigned supervisor and client that guide the students through the design process.

By participating in the multidisciplinary capstone, students learn about functioning and working in a multidisciplinary team environment. Furthermore, they get to work on a real world project with an industry partner.

Based on students' feedback from the undergraduate multidisciplinary course and its success, University of Toronto has introduced a multidisciplinary project based course at the graduate level for Master of Engineering (MEng) students. We introduce the framework of this course in this paper.

There are multidisciplinary graduate programs across the country, but to the best of our knowledge, there exist no multidisciplinary project based course at a graduate level. This is a very novel framework that can revolutionize students' experience at the graduate level.

For example, McGill University has a collaborative program between computer science and engineering. McMaster University has a biomedical program at the 
graduate level that is a collaboration between the faculty of health sciences and the faculty of engineering. But there has been no graduate level program that integrates all the faculties within engineering and outside to collaborate on one platform.

Queens University, University of Calgary, University of British Columbia and University of Waterloo also have incorporated multidisciplinary projects in their undergraduate curricula. The offered courses are all project based courses with or without industry partners. But there has been no graduate level initiative at these universities.

Research shows that in multidisciplinary teams, diverse background knowledge is a key factor for team innovation [2]. To foster innovation, students require an extensive support system to tackle these complicated multidisciplinary projects. In the initial framework [3], subject matter experts were assigned to each project besides the clients and the supervisors. Feedback from students shows that this network and support system should be extended. It should also be more accessible. Faculty expert zone is a new addition to the multidisciplinary project framework to create a better support system for students both in graduate and undergraduate level.

As more institutions join to implement multidisciplinary courses, it is essential to share the qualitative and quantitative data regarding the effectiveness, challenges and viable structure of such initiatives.

\section{MULTIDISCIPLINARY UNDERGRADUATE CAPSTONE COURSE}

From 2013-2014 school year that this multidisciplinary course was established, nearly 240 students have benefited from this course by being exposed to diverse range of projects from engine design to health care delivery to financial algorithm. Fifty-six projects have been completed for 30 clients. As Professor Cristina Amon, the dean of Faculty of Applied Science and Engineering at University of Toronto describes:

"The MCP course has an amazing track of achievement and innovative teaching methods, making it an excellent model for $21^{\text {st }}$ century engineering education."

When students who took the undergraduate capstone course were asked whether they would suggest this course to an upcoming student, $94 \%$ said yes. It was this positive experience of students with the undergraduate multidisciplinary capstone course that laid the foundation for the graduate level MMP course. This section highlights students' experience with the undergraduate course.

The range of offered projects in the undergraduate multidisciplinary capstone is very diverse with projects within aerospace, health, finance, defense, manufacturing, and education that require expertise in Chemical Engineering, Electrical Engineering, Computer Science, Mechanical Engineering, Industrial Engineering, Materials Science, and/or Engineering Science.

In literature, working effectively with people who define problems differently is stated as one of the global competencies for engineers [4]. The students in undergraduate multidisciplinary capstone were able to gain this competency by working with students from other disciplines. A team of students with diverse educational backgrounds pushed students to see the problems from different perspectives. As one Electrical and Computer Engineering student nicely mentioned during the showcase:

"I learned that there are different ways of solving an issue, I tend to look at all the problems as an ECE [Electrical and Computer Engineering] problems and identify ECE solutions for it. Because that's what I know and learned. These guys [Students from Mechanical and Engineering Science background] identified solutions that I would have never taught of. For example, I could not think of any way to stabilize this system without changing the frame, they [Mechanical Engineering Students] managed to stabilize this [UAV-Unmanned Aerial Vehicle] without changing the frame which is what made this design work."

This experience also gave students an opportunity to communicate their disciplinary knowledge to people outside of their disciplines. This is an essential and vital skill set at work and the multidisciplinary capstone experience allows students to learn it and polish their skill by practicing it. We have investigated and analyzed how disciplinary knowledge is applied, taught, and learned among team members in another study last year [5]. Our preliminary findings suggest that students had an open communication among their teams that led to sharing of their disciplinary knowledge. Being is a diverse team led to more communication and learning. They became a better communicator by being aware of their assumptions as one participant describes:

"We [from mechanical engineering] had to explain the terminologies to these guys [from Electrical and Computer Engineering] ... I understood my assumptions when talking to other engineering students."

Students in undergraduate multidisciplinary capstone became aware of their own biases as a result of trying to 
communicate their ideas to their teammates from other discipline. Being part of a multidisciplinary team really mimics a real world experience for students.

Our interviews with more than 20 students in the course revealed that the multidisciplinary nature of the projects was the main driving factor for the student to choose multidisciplinary capstone over their home department's monodisciplinary capstone. The multidisciplinary nature and scope of the projects motivated students to take multidisciplinary capstone. As one participant stated:

"I choose multidisciplinary capstone because I loved the project and none of the projects in mechanical capstone was interesting for me."

Students in the Faculty of Applied Science usually don't get a chance to have a capstone project with an industry client. So the experience of working with an industry partner was one of the important highlights of the multidisciplinary capstone for many students from those departments. One student from the Electrical and Computer Engineering describe her experience as:

"The project was so real, I was so sick of small coding projects...now I actually have something to show to people...This is interesting because there is a real problem and it's [prototype] working."

Flexible project selection in undergraduate multidisciplinary capstone allows students within a specific discipline to try something new and to explore their capabilities. For example, in one project, a mechanical student was given the opportunity to try app development. This experience persuaded that student to change his field of study to computer science for his graduate studies. Another student from Electrical and Computer Engineering was given a chance to do a project in financial industry. The results of our interviews suggested that flexibility for project selection had a positive impact on students' experience. The same flexibility will be offered at the graduate level course.

The current framework for this course also allows students to bring forward their own projects. At University of Toronto more than $50 \%$ of students do their professional experience year before they take their undergraduate capstone course. The current framework allows these students to bring their own projects from the companies in which they interned. These projects benefit the university by bring resources and new connections to the faculty. Also the pre-existing relationship with the industry partner prevents potential conflict and lack of students' motivation for the project. The same policy will be applied for the graduate level course. We anticipate that this positive effect will be higher for graduate students as most of them are coming back to school from industry and they have a pre-exiting relationships.

Our success with undergraduate multidisciplinary capstone course paved the way for the introduction of a similar course at the graduate level in 2015-2016 school year.

\section{MULTIDISCIPLINARY MASTER OF ENGINEERING COURSE}

Many students from our own faculty and across the world decide to pursue MEng to be better prepared for challenges of the 21th century for engineers. MEng students, in their graduate studies, need to acquire broader skill sets and learn to communicate their ideas to peoples in other disciplines so that they can come up with innovative solutions to pressing global problems. University of Toronto's MEng Multidisciplinary Project (MMP) is a graduate-level course that provides $\mathrm{U}$ of $\mathrm{T}$ MEng students with the opportunity to apply their knowledge and skills to address technical research challenges for practical engineering projects of multidisciplinary nature. This program is just introduced in 2015-2016 academic year and hence is in its pilot stage. This course is open to all graduate students within the Faculty of Applied Science and Engineering. This course gives graduate students the opportunity to challenge their technical and communication skills by getting involved in a multidisciplinary industry based project with multiple stakeholders.

A total of 20 faculty members from Electrical and Computer Engineering, Mechanical Engineering, Material Engineering, Civil Engineering, Industrial Engineering, Chemical Engineering, and Institution for Aerospace studies are involved with this course.

This project based course is an extended version of the undergraduate multidisciplinary capstone course. However, the scope of the course is bigger than the undergraduate multidisciplinary course and the projects are more complex. They are also multiple supervisor involved.

Each project in this course requires graduate students from at least 2 different departments to collaborate with each other to solve their assigned problem.

One of the biggest challenges of MMP compared to undergraduate multidisciplinary capstone is the involvement of multiple supervisors. In the undergraduate multidisciplinary capstone there is only one supervisor per project. But for MMP there will be one supervisor for each field of study and discipline that is involved in the project. For example, if for a project, there are students from Electrical and Computer Engineering, Mechanical Engineering and Material Engineering, then three faculty members from each department is assigned to supervisor 
the project. Having multiple supervisors is a challenge in terms of administration. Managing multiple supervisors is also challenging for students as they need to communicate with multiple stakeholders and satisfy their requirements.

Multidisciplinary master projects are essential to any Canadian engineering school with a master of engineering program. The goal of MEng is to enhance student's career opportunities. The opportunity to work with engineers from other disciplines toward solving a problem is a unique experience that fulfills the requirement of the program. Out of the 10 courses required for a MEng degree only 2 can be used toward multidisciplinary projects, leaving students with 8 other technical courses to enhance their knowledge beyond their undergraduate degree.

The goal of MMP is to provide MEng students with the following learning outcomes: contributions to the technical area, broad perspective, teamwork, and interdisciplinary communication skills. These four learning outcomes were identified as the most important learning outcomes for a graduate student from a content analysis of 130 funded proposals from the U.S. National Science Foundation's Integrative Graduate Education and Research Traineeship (IGERT) program [6]. The multidisciplinary graduate course is new to the Canadian universities and the University of Toronto is one of the pioneers of this initiative.

\section{FACULTY EXPERT ZONE}

Projects for both undergraduate and graduate multidisciplinary design courses are sponsored by variety of industries for example health care, finance, aerospace, automotive and etc. This wide range of projects not only requires students from different disciplines to be involved, but it also requires supervisors and Subject Matter Experts (SMEs) from various fields and specialties to be involved.

In the initial framework for the undergraduate multidisciplinary projects, SMEs were assigned to each team to provide extra support and expertise available.

Last year the multidisciplinary courses had 14 SMEs that were representing different department and institutions within the Faculty of Applied Science and Engineering at the University of Toronto (more than 16 faculty members were already involved by supervising the team).

The initial strategy was to assign one faculty member to be the supervisor of the project that is responsible for assessing and meeting with teams on a regular basis to give guidance. But we also provided a team of subject matter experts within the faculty to create the support system for students. In our opinion SMEs are very essential for the scope of eight months projects. If students are not given the right directions or resources, they are not able to finish the project on time.

For example, one of the team was tasked to design a robotic arm by a team of Mechanical and Material students supervised by a Mechanical Engineering faculty. The process of material selection for the arm required a consultation from a material subject matter to guide and direct the material students in the project. So they received support and guidance from a material science professor that was among the SMEs for the course. Such a detailed and specific advices is essential for multidisciplinary projects considering their timeframe.

The result of an online survey from last year's multidisciplinary capstone course shows that around 50\% of students did not use their SMEs or did not approach them. When students asked "I or my teammates ask someone outside of the team and not the client or supervisor for help resolving a design problem", 57.14\% did seek out for help and support. When asked "I or my teammates review the design with people outside of the team who are not the client or supervisor ", $46.7 \%$ consulted with someone other than their supervisor and client. When asked "I or my teammates obtain materials or resources from people outside of the team who are not the client or supervisor", 55.24\% of the students obtained resources from outside. This data shows that it was useful and critical for some of the students to get access to SMEs, but not all of them were able to reach out. This might be because of the overwhelming nature of the course for some of the students.

These observations lead us to initiate the faculty expert zone which will be an extension of the subject matter experts in the course. The faculty expert zone will be available to both undergraduate and graduate students with multidisciplinary projects. The goal is to expand our resources to encompass the whole faculty as a support system for multidisciplinary projects.

Student can seek help and guidance from different engineering faculties that are subject matter experts. They also can seek help and guidance regarding professional communication. Engineering communication program has partnered with multidisciplinary courses to help students excel in their technical analysis and on how they would communicate and present their technical analysis to the clients or any external members. This includes any advice and guidance regarding reports, presentations, posters and any other form of external and internal communication.

The goal of faculty expert zone is to collect all the area of expertise from faculty across the board, which makes it easy to access faculty members and engage them in multidisciplinary projects. Another great advantage of building the faculty expert zone is to give students access to as many facilities as possible for multidisciplinary projects. The main takeaway point here is that by growing the numbers of projects, different industries and skill sets 
required for this demanding multidisciplinary education, there is a need for an extensive support system by faculties and even graduate students across the faculty.

Matusovich argues that "Transformative change in higher education requires a continuous interplay between educational research and educational practice" [7]. The faculty expect zone act as a gateway for professors with strong research contribution to applies and engage their research into engineering education.

The need for this support system due to the nature of projects is one of the many different between departmental capstones and multidisciplinary capstone. The faculty expert zone is introduced to provide a network of support and consultation. The assessment and evaluation is still under supervisors' roles and responsibility. Thus, faculty members in the faculty expect zone are not responsible for assessing students. They are providing only consultation when necessary to direct and guide the students in the right direction and provide them with their world class research expertise.

This unique support system from our faculty will enhance students' experience and provide them with endless opportunity. Faculty expert zone will create a faculty vide structure to make a true multidisciplinary experience for students possible.

\section{CONCLUSION}

Multidisciplinary approaches are vital to solving the most pressing engineering challenges. University of Toronto has initiated multidisciplinary project based courses both at the undergraduate level and at the graduate level to better prepare students for today's multidisciplinary workforce. The outcomes of our interviews suggest that students were motivated about the projects with multidisciplinary nature. The projects taught students to look at a problem from multiple perspectives. Students had a very positive overall experience working on an eight months long industry sponsored project with students from different disciplines. This positive feedback along with the industries expectation of graduating student with multidisciplinary experience led to the development of the MMP.

Projects with multidisciplinary nature require students from different disciplines to work with supervisors and faculty advisors with different expertise. Faculty Expert Zone was created to provide a support system for students. Faculty Expect Zone is one of the many ways that research can enrich teaching specifically for institution like University of Toronto which is a pioneer in research.

\section{Acknowledgements}

The authors would like to thank the Natural Sciences and Engineering Research Council of Canada (NSERC) for funding this research through the Chairs in Design Engineering (CDE) grant.

\section{References}

[1] Nathan Hotaling, Barbara Burks Fasse, Lewis F. Bost, Christopher D. Herman, and Craig R. Forest, "A quantitative analysis of the effects of a multidisciplinary engineering capstone design course," Journal of Engineering Education, vol. 101, no. 4, pp. 630-656, 2012.

[2] Robert T. Keller, "Cross-functional project groups in research and new product development: diversity, communications, job stress, and outcomes," Academy of Management Journal, vol. 44, no. 3, pp. 547-555, 2001.

[3] Kamran Behdinan, Remon Pop-Iliev, and Jason Foster, "What constitutes a multidisciplinary capstone design course? best practices, successes and challenges," in Proc. 2014 Canadian Engineering Education Association, CEEA14 (Canmore, AB; 8-11 June 2014), 5 pp., 2014.

[4] J. C. Swearengen, Spencer Barnes, Steven Coe, Carsten Reinhardt, and K. Subramanian, "Globalization and the undergraduate manufacturing engineering curriculum," Journal of Engineering Education, vol. 91, no. 2, pp. 255261, 2002.

[5] Mario Milicevic, Narges Balouchestani Asli, Deborah Tihanyi, and Kamran Behdinan, "An exploration of communication and knowledge application in multidisciplinary undergraduate engineering capstone design teams," in Proc. 2015 Canadian Engineering Education Association, CEEA15 (Macmaster University, ON), 2015.

[6] Maura Borrego, and Stephanie Cutler, "Constructive alignment of interdisciplinary graduate curriculum in engineering and science: an analysis of successful IGERT proposals," Journal of Engineering Education, vol. 99, no. 4, pp. 355-369, 2010.

[7] Holly M. Matusovich, Marie C. Paretti, Lisa D. McNair, and Cory Hixson, "Faculty motivation: a gateway to transforming engineering education," Journal of Engineering Education, vol. 103, no. 2, pp. 302-330, 2014. 